\title{
'No sanctuary': Missed opportunities in health and social services for homeless people with dyslexia?
}

\author{
Stephen J Macdonald ${ }^{1}$ and Lesley Deacon ${ }^{2}$
}

\begin{abstract}
This paper examines the relationship between dyslexia, homelessness and access to health and social services. This is a quantitative study analysing data from the Multiple Exclusion Homelessness across the United Kingdom Survey. Data was collected from 443 participants who had experienced some form of homelessness in the UK. A comparison was made between people with dyslexia and those homeless people without this condition. The data findings in this paper appear to reveal that people with dyslexia are overrepresented within the survey's homeless population. It may be expected that people with dyslexia might not come in contact with health professionals and social workers as support for this condition generally takes place within an educational environment. Yet this study seems to indicate that homeless people with dyslexia have greater contact with health professionals and social workers compared with non-dyslexic homeless people. This paper suggests that health and social services need to consider conditions like dyslexia in order to develop support for this particular group of people that have experienced homelessness.
\end{abstract}

Keywords: dyslexia; homelessness; adult services; social work; health care; education

1. Senior Lecturer in Social Sciences, University of Sunderland

2. Senior Lecturer, Applied Social Studies/Social Work, University of Sunderland

Address for correspondence: Dept of Social Sciences, Faculty of Education and Society, University of Sunderland, Priestman Building, Green Terrace, Sunderland, SR1 3PZ. UK. stephen.j.macdonald@sunderland.ac.uk 


\section{Introduction}

The aim of this paper is to analyse data on the experiences of homeless adults with dyslexia and to consider whether there may be opportunities for early intervention by health and social work professionals. A quantitative comparison will be made between people with dyslexia $(\mathrm{N}=68)$ and people without dyslexia $(\mathrm{N}=375)$ that have experienced homelessness. The paper attempts to discover if there are any correlations $(\mathrm{P} \leq .05)$ relating to homelessness, dyslexia and access to health and social services. Within the data findings, it is implied that people with dyslexia become homeless earlier in their lives and are more likely to be described as experiencing 'episodic' or 'chronic' homelessness compared with people without dyslexia (Lee et al. 2010).

The specific focus of this paper will discuss how the data implies that there are a number of opportunities where service providers could intervene to try and prevent the escalation of homelessness for dyslexic participants. Over the past 30 years social and health services have been developed and aimed at the needs of homeless people with mental health problems or intellectual disabilities (Taylor at al. 2010; Pluck et al. 2011; Hore 2013). The literature indicates that contemporary services must broaden their scope beyond mental health problems support; and this data suggests that specific issues affecting people with dyslexia should be considered by homeless service providers.

\section{Defining homelessness}

Lay-perceptions of homelessness predominantly portray individuals as not having access to housing and sleeping 'rough' on the streets of towns and cities (Crane, et al. 2001; Lee et al. 2010). Yet this is only one group of a larger population of people that are defined in legislation as 'homeless'. Farigaig (2012: 763) gives the definition of homelessness as 'accommodation which does not meet the prevailing cultural standard in terms of facilities or security of tenure. This includes rough sleeping or squatting, 'couch surfing' ... or stays in refuges [i.e. hostels]'. Lee et al. (2010) suggest that patterns of homelessness fall into three clear categories which are defined as transitional, episodic and chronic.

The first group labelled as transitional refers to a temporary and brief homeless period where people move in with family or friends which can be described as a singular life event. The second group is defined as episodic and can be described as temporary re-occurring cycles of homelessness which are over short periods of time. In research by Crane and Warnes (2001), they assert that it is this group that have a range of hidden unmet needs and often fall between health services, housing, and social services. Therefore, this group are more difficult to identify as they are less 
visible than people living on the streets of towns and cities. Finally, the last group is referred to as chronic. This refers to individuals that experience long periods and permanent states of homelessness (Colane 2007, Lee et al., 2010). It is this group that usually defines the social perception of homelessness as these individuals are often visible as they are living on the streets of our major cities. Lee et al. (2010) suggest that although chronic homelessness is over represented in social research, this is actually the smallest homeless population of the three categories.

The vast majority of people defined as homeless are individuals living in temporary or transitional accommodation with no permanent living residence. Official government figures for homelessness in England alone state that there are 60,490 households in temporary accommodation, with 43,420 of these households having dependent children (DCLG 2014). These figures do not include what Reeve and Batty (2011) refer to as 'hidden homeless', and although there are no accurate figures on this, they estimate that this population is between 310,000 and 380,000 at any given time (Reeve and Batty, 2011: 13). With reference to chronic homelessness, the DCLG (2013) figures also reveal that there are an additional 2,414 people sleeping rough on the streets of England.

In the UK, homelessness has been identified as a social problem by a number of social welfare policies aimed at housing provision over the last four decades (Manthorpe 2013). The Housing (Homeless Persons) Act (1977) set out criteria which defined 'priority need groups' that could be considered at risk of becoming homeless in England and Wales (Lund 2007; Manthorpe et al. 2013). Support was predominantly aimed at families/single parents with dependent children, or families experiencing homelessness through emergency flooding, fire or other disasters. Furthermore, there was recognition of certain groups within society which were considered vulnerable as a result of, mental and learning disabilities, physical disabilities and old age (Lund 2007; Manthorpe 2013). This policy was amended in the Housing Act (1996) and gave local authorities a legal responsibility to house the 'priority need groups' within their local areas.

The list of at risk groups were extended further in the Homelessness Act of 2002 where 'vulnerability' was expanded to include, young adults aged between 16 and 17, care leavers between 18 and 20, victims of domestic violence, people leaving the Armed Forces and offenders having served a custodial sentence. Furthermore, local authorities can no longer justify just offering temporary accommodation to people experiencing homelessness as the 2002 Act also states that individuals outside the 'at risk groups' must also be eligible to receive support to eradicate homelessness within England and Wales. Local authorities now have a legal duty to give 24-hour advice and support for people who are experiencing, or are at risk of experiencing, homelessness. The Act made it clear that any individual at risk of becoming homeless must receive support although this only refers to individuals defined as 'statutory homelessness'.

For statutory homeless people's access to services within a 24 hour period is 
legally enshrined, yet for the non-statutory group Local Authorities do not have a duty to secure accommodation (Wilson 2015). The non-statutory group consists of people outside of the 'at risk' groups such as illegal immigrants, people without a local connection, intentional homeless people, etc. As Wilson (2015) states 'single people and couples without children who are not deemed to be vulnerable for some reason (e.g. as a result of their age or physical/mental ill health)' could be defined as non-statutory. Furthermore, although the Homelessness Act (2002) aims to eradicate homelessness and protect vulnerable members of the community from becoming homeless, this protection only extends to European Union citizens. Therefore, this excludes anyone without EU citizenship resulting in a two tier system of support in the UK.

\section{Dyslexia and homelessness}

As Markos and Strawser (2004) and Patterson et al. (2012) note, studies that discuss disability within the homeless literature are, to a certain degree, dominated by the notion of mental health problems; as a result very few studies have investigated links between dyslexia and homelessness. An early study which did this was conducted by Barwick and Siegel (1996) in the US. They suggested that there was an overrepresentation of people with reading or writing disabilities within the US homeless population. Within their research, Barwick and Siegel (1996) suggest that $52 \%$ of their sample of homeless young people showed symptoms of specific learning difficulties ${ }^{1}$. They indicate how their analysis is significantly higher than the $4 \%-10 \%$ of people with dyslexia in the general population. However, their research dismissed an association between poor school attendance and pathways into homelessness. They found no statistical association between poor school attendance for people with dyslexia, in comparison with that of poor school attendance in the non-dyslexic population.

Although they dismissed educational disengagement as a risk factor for the dyslexic population, they suggested there may be a link between the 'defects' of dyslexia and homelessness. Yet a review of the research literature by Markos and Strawser (2004) indirectly disputes Barwick and Siegel's research findings. They suggest that homelessness for people with dyslexia was not because of symptoms of dyslexia but due to issues of social disadvantage and multiple and complex forms of social exclusion (Manthorpe et al. 2013). For Markos and Strawser (2004) the key issue which led to an increase of people with dyslexia in the homeless population was due to issues of unemployment and poverty. They suggest that people with dyslexia are particularly vulnerable to unemployment especially if they are from a lower socio-economic background. Hence, for people with dyslexia they argue that homelessness is a result of poor educational provision and other aspects of social 
disadvantage such as abuse or addiction problems. In research by Patterson et al. (2012) in Canada, they also found that dyslexia was overrepresented within their homeless population. Again they suggested an intersectional relationship linking dyslexia with poor physical health, poor mental health and substance misuse all resulting in risk factors into homelessness. Patterson et al. (2012) implied that specific learning difficulties might be a strong predictor for pathways into homelessness in adulthood.

In UK research conducted by Olisa et al. (2010) with 101 formerly homeless people accessing services also discovered high levels of poor literacy in their homeless sample. Olisa et al. (2010) found that 55\% of participants had significant difficulties with general literacy problems. They suggest that poor literacy had undermined relationships for their homeless participants as 28\% suggested it affected their employment opportunities, $20 \%$ stated it affected their self-esteem, and a further $17 \%$ reported this made it more difficult for them to keep in contact with family and friends (Olisa et al. 2010). Similarly Nalavany et al. (2013: 58) raised concerns regarding self-esteem across the general adult dyslexic population and refer to this as living with a 'concealable stigmatised identity'.

Although Olisa et al.'s study could not make a direct link between dyslexia and homelessness due to problems with diagnosis (because of the intersectional nature of other presenting mental health issues), they highlight the prevalence of literacy difficulties within their research participants. Their research focused on key barriers constructed in education relating to adult literacy classes which excluded rather than included dyslexic learners. These classes were accessed by homeless people, yet Olisa et al. (2010) reported that these classes were not equipped to deal with adults with complex social and literacy needs. Therefore, in support of Patterson et al. (2012) research, inferior educational experiences seem to lead to low self-esteem and for some people develop into severe issues of stress, anxiety, depression and in some cases substance misuse.

As Markos and Strawser (2004) suggest, over the past 30 years social and health services have been developed aimed at the needs of homeless people with mental health problems or intellectual disabilities. This is not the case for people with dyslexia, as there are almost no specific interventions aimed at reducing risk factors experienced by homeless individuals with dyslexia (Patterson et al. 2012). Although all of these studies highlight the importance of acknowledging that dyslexia plays a part into pathways into homelessness, they also suggest that these risk factors are interlinked with other forms of social exclusions. As Fitzpatrick, et al. (2012) and Manthorpe et al. (2013) illustrate there is growing evidence that homeless people experienced multiple and complex forms of social exclusion which they refer to as 'multiple exclusion homelessness'. Therefore, this literature seems to suggest that dyslexia may be one of these forms of exclusions within this framework presented by these authors. 


\section{Early intervention and potential opportunities}

As Markos and Strawser (2004) suggest, health and social work services have developed independent systems that support people with mental health problems and intellectual impairments; what has not developed is a system that targets the specific needs of homeless people with dyslexia that are experiencing crisis. When examining UK social care policy over the last decade, Local Authorities have been concerned with adapting models to reduce the need for the support of long term care needs. This has been achieved by focusing on prevention and early intervention as well as raising the eligibility criteria for individual packages of care and support to substantial/critical needs (National Audit Office, 2014). Since the 1940s there has been a shift away from institutional care to care within the community (Crane and Warnes 2001). Within England and Wales, inter-professional working has been viewed as fundamental in order to develop a successful model of community care. The statutory framework developed in the NHS and Community Care Act (1990) entrenched inter-professional working within the assessment of needs process. The Act introduced the concept of 'Assessment and Care Management' (Cornes et al. 2011). This introduced a holistic approach to health and community care services. As Cornes et al. (2011) illustrates this brought together services from the housing authority, social services and the NHS. This was followed by in the Care Act 2014 which attempts to draw together the previously disparate legislation regarding the duty of Local Authorities in relation to the social care of adults with needs, and carers. A specific focus of this new legislation is on prevention. Section 2 states 'A local authority must provide or arrange for the provision of services, facilities or resources, or take other steps, which it considers will (a)contribute towards preventing or delaying the development by adults in its area of needs for care and support' (Care Act 2014). This focus would suggest that early intervention should encourage the identification of relational factors in people's lives that lead them to require higher levels of support, for example in relation to homelessness.

According to the report by the DCLG and DCSF (2008: 5) 'the number of young people becoming homeless has remained disproportionately high, reducing the life chances of too many 16 and 17 year olds and young care leavers'. Instead the focus for practitioners should be to 'prevent failure [rather] than tackle a crisis later' (p.11). This main focus on prevention along with the development of pathways (DCLG, 2012) is through early identification of risk factors and partnership working between agencies and professionals (Manthorpe 2013). Risk factors for young people include, but are not limited to,

disruptive or antisocial behaviour ... involvement in or risk of offending... poor attendance or exclusion from school... [and] disengagement from education, training or employment post 16. (DCLG and DCSF, 2008, p.25) 
Yet there is no reference to explicit issues relating to specific learning difficulties or associated issues.

Young people coming to the attention of housing authorities (or other agencies) are likely to be at risk from additional needs and therefore should be subject to the Common Assessment Framework (CAF) for these needs to be identified and supported (Manthorpe 2013). (The CAF follows statutory guidance in relation to children and families as set out in the Children Act 2004.) However within this guidance, and other methods of assessment, the multi-agency professionals working together may not identify opportunities to focus on lower-level learning variations (i.e. dyslexia). Whilst disengagement from education may be a factor, there would likely be reliance by other practitioners on those in schools to identify potential learning variations such as dyslexia (Macdonald 2009).

Whether this issue would then be considered a significant factor would depend on individual practitioner's knowledge and ethos in this area (Reindal 2008). If not identified within schools, social work practitioners (for example) are not required to identify learning problems associated with dyslexia, so it is unlikely they would recognise these potentially significant factors (Markos and Strawser 2004). Beddow (2011) suggests that training in social work can be focused on the immediate specific needs of the job at the time; so even if social work practitioners are working based on evidence-informed practice, unless dyslexia was recognised as a contributing factor in homelessness it is unlikely that social work practitioners would receive this specific training. As Macdonald (2009) asserts there is a lack of recognition of the impact that dyslexia has on adulthood outside of education. In relation to Patterson's study, the significance of people with dyslexia being over-represented in the homeless population would suggest the potential is there for early intervention (Patterson et al. 2012). Whilst government policy may provide overarching direction for practitioners the experience for individuals is varied. What is evident here is that there is a current lack of focus on the significance of conditions like dyslexia from homeless service providers and how this might be linked to social exclusion (Macdonald 2009; Yates 2013) and homelessness (Patterson et al. 2012).

\section{The social relational model of disability}

The present study is influenced by a critical realist approach to disability and impairment, and this article applies a 'social relational model of disability' to the data analysis (Reindal 2008). Therefore, the authors recognise the interactional elements of disability and impairment at the molecular, biological, psychological and sociological levels (Danermark 2007). In this approach, impairment is acknowledged, as this study uses it as a framework of analysis (dyslexia diagnosis). Hence, rather than automatically rejecting the psycho-medical models, this study views these models 
as useful when commenting on issues of impairment (symptoms and neurological structures). Such models only become oppressive when they attempt to explain social issues (such as homelessness) within a medical context (Macdonald, 2010).

Homelessness is a social condition, because it is society that constructs social and cultural norms, maintained by housing policy and living conditions. The route into homelessness is not determined by biological neurological 'weaknesses' but rather by structural and environmental issues. If people with dyslexia are more likely to become homeless, from a social relational model perspective this could be due to both 'personal' social restrictions and 'imposed' social restrictions. The social relational model still allows a possible distinction between 'disability' as disabling structural barriers and 'impairment' as biological/neurological variations, but acknowledges that one cannot exist without the other (Reindal 2008). Thus, limitations are due to a significant neurological variation (i.e. dyslexia), the failures of schools to identify and adequately support children with dyslexia resulting in psychological implications (alienation), and disabling barriers in the form of structural exclusion in education, health/social services and job markets, etc. (Reindal 2008; Shakespeare 2013). It is suggested that all of these factors interact and feedback at each level resulting in an increased risk of social exclusion (Shakespeare 2013).

\section{Methodology}

This study has attempted to analyse quantitatively the relationship between dyslexia and the increased likelihood of a person becoming homeless. The data in this study was obtained from the 'Multiple Exclusion Homelessness across the United Kingdom Survey' accessed through the Data Archives UK Service (Fitzpatrick, et al. 2010). The fieldwork was comprised of a questionnaire survey and extended interviews which were conducted in 2010 by Fitzpatrick, et al. Their survey collected information on participants who had experienced multiple exclusion homelessness (MEH). They examined the complexities of homelessness with reference to the intersectional relationships between homelessness, substance use, mental health and institutional care (Fitzpatrick, et al. 2012). The data was collected by Fitzpatrick, et al. (2010) who worked in partnership with organisations such as street outreach teams, drop in services, day centres, direct access accommodation, soup runs, etc. From these groups, six services were randomly selected from different geographical locations (Leeds, Belfast; Birmingham; Bristol; Cardiff; Glasgow; and London) to obtain a population sample.

Within the MEH survey there was an in-depth section on health issues and disability. The MEH survey collected information on participants who had experienced homelessness and had some form of learning difficulties. For this present analysis, information was extracted in order to analyse the experiences of homeless 
participants that had self-reported as having dyslexia. Hence in this paper, the research compared two groups of participants that have experienced homelessness and used them as the independent variable. The first group consists of participants $(\mathrm{N}=68)$ who have experienced homelessness and who have dyslexia. The second group consisted of individuals ( $\mathrm{N}=375$ ) without dyslexia who have also experienced homelessness. Information was collected in this survey on participant's dyslexia diagnosis by means of self-reporting. (The authors acknowledge the limitations to this method when collecting data on disability and in particular dyslexia).

The data was analysed using SPSS in the form of single variable analysis (univariate), and where data was calculated to be significant (P $\leq .05)$, bivariate analysis was also applied (De Vaus 2002). Two or more variable frequency distributions were analysed to discover if variables are statistically independent or if they are correlated (De Vaus 2002). In the following analysis, descriptive statistics have been used in the form of cross-tabulation and One-way-ANOVA tests to examine distribution of cases when examining the correlation between two or more variables. The data from this survey was subsequently analysed and only data was used which was calculated to be of statistical significance $(\mathrm{P} \leq .05)$.

\section{Findings}

\section{Social demographics and Dyslexia}

It should be noted that within the social demographics at the multivariate stage of analysis, dyslexia did not have a significant impact on variables concerning sex, age or ethnicity. Hence, there was no ratio difference between the dyslexic and nondyslexic groups in relation to sex, age and ethnicity. In both groups, males were overrepresented compared with females (males $=79.4 \%$ and females $=20.6 \%$ ). In both groups age demographics reveal a steady increase in homelessness between 16 to 34 years which peaks at the 45 year age group $(16-34=38.3 \%$; $35-54=50.4 \%$; $55+=11.3 \%)$. After this age group homelessness steadily decreases dramatically in the 55 year plus category. In relation to ethnicity for each group, 94\% were European citizens and only $6 \%$ reported having been born outside of Europe (UK citizens= 78.3\%; European= 15.3\%; non-European= 6.4\%).

\section{Dyslexia and homelessness}

As illustrated, dyslexia and homelessness has been under researched within the research literature. For the few studies that have examined the relationship between dyslexia and homelessness there has been a general consensus that people with 
dyslexia are overrepresented within the homeless population; these figures have suggested a range from $46 \%$ to $52 \%$ of their sampled population had dyslexia (Barwick and Siegel 1996; Olise 2010; Patterson et al. 2012). When examining if dyslexia was overrepresented within the present analysis, $15.3 \%$ of participants reported having dyslexia. Although lower than previous studies, this figure is higher than the prevalence in the UK's general population which is estimated at between $4 \%$ and $10 \%$ (Semple et al. 2013). Hence, data in this survey seems to indicate that people with dyslexia are between $5 \%$ and $11 \%$ overrepresented within this homeless sample.

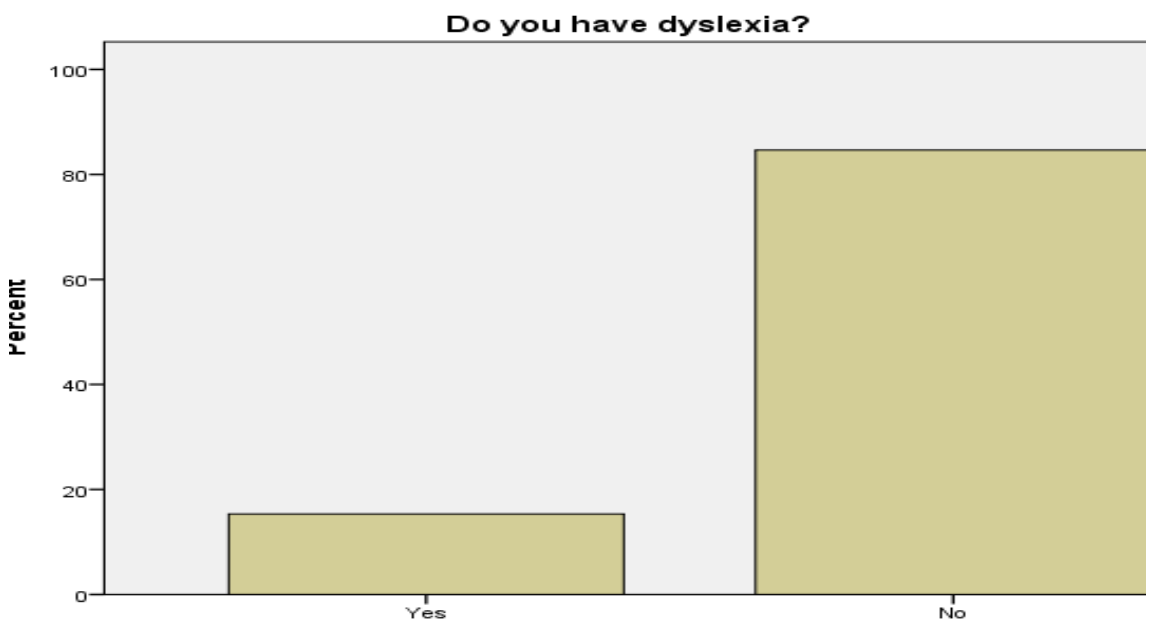

Figure 1: Dyslexic and non-dyslexic population

\section{Adult homelessness}

When examining the experiences of adult homelessness a number of significant differences ( $\mathrm{P} \leq .01)$ appeared within the data analysis. The findings in table 1 suggest that the dyslexic group experienced episodic or chronic homelessness earlier in their lives compared with the non-dyslexic group. This claim seems to be supported as participants with dyslexia described first sleeping rough on average at the age of 22 compared with that of 29 years for the general homeless population. On average people with dyslexia first stayed in a hostel/shelter at the age of 26 years, compared to the non-dyslexic population who reported their first stay in a hostel was at 30 years. Participants with dyslexia also indicated that they had become homeless more times compared with the general homeless population. These participants reported experiencing homelessness on average 11 times compared with the non-dyslexic group who on average experienced homelessness nine times. A significant difference also appeared in relation to the amount of time people slept rough over their lifetimes. 
The dyslexic group reported sleeping rough on average for five years compared with the non-dyslexic group indicating 3.5 years. In general, these findings seem to imply that people with dyslexia are at an increased risk of becoming either episodic or chronic homeless compared to the general homeless population.

Table 2

Severity of homelessness within the adult sample

\begin{tabular}{|c|c|c|c|}
\hline \multicolumn{4}{|l|}{ Experiences of Homelessness } \\
\hline & & & Sig. \\
\hline \multirow[t]{2}{*}{ Age first stayed in hostel/ night shelter } & Dyslexic & Mean $=26$ years & \multirow[t]{2}{*}{$\mathrm{P}=.01$} \\
\hline & Non-dyslexic & Mean $=30$ years & \\
\hline \multirow[t]{2}{*}{ Age of homelessness (slept rough) } & Dyslexic & Mean $=22$ years & \multirow[t]{2}{*}{$\mathrm{P}=.00$} \\
\hline & Non-dyslexic & Mean = 29 years & \\
\hline \multirow[t]{2}{*}{ Number of times of homelessness } & Dyslexic & Mean $=11.1$ times & \multirow[t]{2}{*}{$\mathrm{P}=.00$} \\
\hline & Non-dyslexic & Mean $=9.5$ times & \\
\hline \multirow[t]{2}{*}{ Years spent sleeping rough } & Dyslexic & Mean $=5.1$ years & $\mathrm{P}=.05$ \\
\hline & Non-dyslexic & Mean $=3.5$ years & \\
\hline
\end{tabular}

\section{Access to services}

Within the data analysis there were a number of significant differences (P $\leq .05)$ which appeared in relation to how people accessed health and social services. As we can see from table three, $50 \%$ of participants with dyslexia have access to a social worker compared with $36 \%$ of the non-dyslexic group; $47.1 \%$ of participants with dyslexia received support from a drugs worker compared to $30.4 \%$ of the non-dyslexic group (i.e. it should be noted that $43 \%$ of dyslexic participants reported using illegal drugs in the past month compared to $27 \%$ of the non-dyslexic group, $\mathrm{P} \leq .01$ ). Furthermore, $44.1 \%$ of participants with dyslexia have contact with a probation worker and $38.2 \%$ a psychiatric professional. This is compared to $31.2 \%$ of the non-dyslexic group accessing a probation worker and $26.9 \%$ of non-dyslexic participants having contact with a psychiatric professional.

Although participants with dyslexia have had increased access to social and health professionals this does not seem to have impacted on reducing pathways into homelessness. This data might indicate a number of missed opportunities in order to confront the intersectional experiences of inequality, abuse and a lack of professional understanding for this specific group. This data might support Olise, et al.'s, (2010) suggestion that although dyslexic participants often engage in services, because services do not adjust their practices with reference to dyslexia, this leads 
to many participants disengaging with the support on offer by these practitioners. Whilst Nalavani et al.'s (2013) study raises the issue of adults with dyslexia as an invisible, stigmatised and marginalised group, they emphasise the importance of family support in raising the self-esteem of these adults. This needs further investigating in the dyslexic homeless population as the nature of their homelessness suggests a lack of support.

Table 3

Participant's use of Services

\begin{tabular}{|l|l|l|l|l|}
\hline Access to Services & & Yes \% & No $\%$ & Sig. \\
\hline Social Worker & Dyslexic & 50 & 50 & $\mathrm{P}=.02$ \\
\hline & Non-dyslexic & 36 & 64 & \\
\hline Drug Worker & Dyslexic & 47.1 & 52.9 & \multirow{2}{*}{$\mathrm{P}=.00$} \\
\hline \multirow{2}{*}{ Probation Officer } & Non-dyslexic & 30.4 & 69.6 & \\
\hline \multirow{2}{*}{$\begin{array}{l}\text { Community Psychiatric Nurse/ } \\
\text { Psychologist / Psychiatrist }\end{array}$} & Dyslexic & 44.1 & 55.9 & \multirow{2}{*}{$\mathrm{P}=.03$} \\
\cline { 1 - 4 } & Non-dyslexic & 31.2 & 68.8 & \\
\cline { 1 - 4 } & Dyslexic & 38.2 & 61.8 & \multirow{2}{*}{$\mathrm{P}=.05$} \\
\cline { 2 - 4 } & Non-dyslexic & 26.9 & 73.1 & \\
\hline
\end{tabular}

\section{Conclusion}

It is recognised by the authors that the data presented in this paper only allows an initial, but important, analysis of the experiences of people with dyslexia. This research should be seen as a starting point for future studies in health and social care into the level of recognition and support that people with specific learning difficulties receive in contemporary practice. This paper has presented evidence that people with dyslexia are overrepresented within the homeless population in the UK. As demonstrated, a number of statistically significant relationships have appeared within the data findings. These findings seem to suggest that for participants with dyslexia, once they become homeless, they have an increased risk of spiralling into the episodic and chronic homeless population. This study does not reject the importance of current support packages with reference to financial stability, drug and alcohol services and mental health support (Taylor et al. 2006; Yates 2013). However, there also seems to be a need for specialist forms of support for dyslexia which is demonstrated in the findings; which requires further research.

Therefore, this study might suggest that there have been numerous opportunities by service providers in order to help people with dyslexia out of multiple social 
exclusions and homelessness (Fitzpatrick, et al. 2012). The data seems to indicate that contemporary services must broaden their scope beyond mental health support in order to include explicit issues that affect people with dyslexia and other specific learning difficulties (Markos and Strawser 2004; Olisa 2010; Patterson et al. 2012). To coincide with Markos and Strawser's (2004) proposal, specific educational support must be integrated into current housing, health and social welfare policy and strategies to help this group break the cycle of homelessness (Macdonald 2009). By doing this, health and social work practitioners have a chance to effectively deal with the multiple problems experienced by people with dyslexia that have become homeless (Patterson et al. 2012).

\section{Limitations}

Despite the strength of the overall design of this study a number of limitations must be considered. Firstly, when analysing data from a secondary source the questionnaire design and type of questions asked is out of the control of the researchers. Secondly, all variables are based on self-reporting and there is the possibility that participants might have unintentionally misinformed researchers collecting data in this survey. Finally, this type of data analysis only allows a very broad overview of social exclusion with reference to the complex experiences of homeless individuals with dyslexia. Further qualitative research is needed in order to explore the complexities of homelessness and dyslexia. A more in-depth analysis needs to take place in order to examine the perceptions of homeless people with dyslexia; regarding how professionals have engaged and supported them outside of the education system.

\section{Note}

1. The term 'specific learning difficulty' replaces the American term of 'learning disabilities' which makes reference to children/adults with severe difficulties in reading, writing, spelling or mathematics i.e. dyslexia. This is to prevent any confusion as in the UK 'learning disabilities' often refers to an intellectual impairment. 


\section{References}

Barwick, M.A., and Siegel, L.S. (1996). Learning difficulties in adolescent clients of a shelter for runaway and homeless street youths. Journal of Research on Adolescence, 6, 649-670

Basu, S. and Stuckler, D. (2012) The Body Economic: Why Austerity Kills. London: Penguin

Beddow, L. (2011) 'Investing in the Future: Social Workers Talk about Research' British Journal of Social Work, 41, 557-75

Berk-Clark, C. V. McGuire, J. (2013) Elderly homeless veterans in Los Angeles: Chronicity and precipitants of homelessness American Journal of Public Health. 103, 2, 232-238

Burns, J. K. (2009) Mental Health and inequity: A human rights approach to inequality, discrimination, and mental disability. Health and Human Rights. 11, 2, 19-31

CLG (2014) Homelessness Statistics: London: Department for Communities and Local Government

Cornes, M., Manthorpe, J., Joly, L. and O'Halloran, S. (2014), Reconciling recovery, personalisation and Housing First: Integrating practice and outcome in the field of multiple exclusion homelessness. Health \& Social Care in the Community, 22, 134-143

Crane, M. and Warnes A.M. (2001) The responsibility to care for single homeless people. Health and Social Care in the Community, 9, 6, 436-444

Critchley, M. (1968) Reading retardation, dyslexia and delinquency. The British Journal of Psychiatry 114: 1537-47

Danermark, B. (2007) Interdisciplinary research and critical realism: The example of disability research. Journal of Critical Realism. 5, 1, 56-64

DCFS (2009) Building a Safe Confident Future: The Final Report of the Social Work Task Force. London: DCFS

De Vaus, D.A. (2002) Surveys in Social Research. London: UCL Press

Department for Communities and Local Government and Department for Children, Schools and Families (2008) Joint Working Between Housing and Children's Services Preventing Homelessness and Tackling its Effects on Children and Young People. London: Department for Communities and Local Government and Department for Children, Schools and Families

Department for Communities and Local Government (2012) Making Every Contact Count: A joint approach to preventing homelessness. London: DCLG

Dyslexia Action. (2005) The Incidence of Hidden Disabilities in the Prison Population. Egham: Dyslexia Action

Farrell, D. (2012) Understanding the psychodynamics of chronic homelessness from a self -psychological perspective. Journal of Clinical Social Work, 40, 337-347

Farrugia, D. (2011) Youth homelessness and individualised subjectivity. Journal of Youth Studies 14, 7, 761-775

Fitzpatrick, S. Pawson, H. Bramley, G. and Wilcox, S. (2010), Multiple Exclusion Homelessness across the United Kingdom, [computer file]. Colchester, Essex: UK Data Archive [distributor], December 2011. SN: 6899, http://dx.doi.org/UKDA-SN-6899-1

Fitzpatrick, S. Pawson, H. Bramley, G. and Wilcox, S. (2012) The Homelessness Monitor: England. York: Institute for Housing, Urban and Real Estate Research, Heriot-Watt 
University and Centre for Housing Policy, University of York

Gill, M. (2011) Educating the professional social worker: challenges and prospects. Social Work Review, 4, 34-40

Gustavsson, A. (2004). The role of theory in disability research: Springboard or strait-jacket? Scandinavian Journal of Disability Research, 6, 1, 55-70

Hore, B. (2013). Is homelessness a matter of social justice for counselling psychologists in the UK? Counselling Psychology Review, 28, 2, 17-29

Kirk, J, and Reid, G. (2001) An examination of the relationship between dyslexia and offending in young people and the implications for the training system. Dyslexia 7, 77-84

Lee, B. A., Tyler, K. A. and Wright, J.D. (2010) The new homelessness revisited. Annual Review of Sociology. 36, 1, 501-521

Lund, B. (2011) Understanding Housing Policy. (2nd ed,) Bristol: Policy Press

Macdonald, S.J. (2009) Windows of reflection from adults with dyslexia: Conceptualising dyslexia using the social model of disability. Dyslexia: An International Journal of Research and Practice. 15, 4, 347-362

Macdonald, S.J. (2010) Towards a social reality of dyslexia. British Journal of Learning Disabilities. 38 (1), 21-30

Macdonald, S. J. (2012) "Journey's End": statistical pathways into offending for adults with specific learning difficulties. Journal of Learning Disabilities and Offending Behaviour. 3, 2, 85-98

Manthorpe, J., Cornes, M., O'Halloran, S. and Joly, L. (2013) Multiple exclusion homelessness: the preventive role of social work. British Journal of Social Work, 1, 45, 1-13

Markos, P. A. and Strawser S., (2004) The relationship between learning disabilities and homelessness in adults. Guidance \& Counselling, 19, (2), 1-24

Means, R. (2007) Safe as houses? Ageing in place and vulnerable older people in the UK Social Policy and Administration, 41, 1, 65-85

Mercier, C. and Picard, S. (2011) Intellectual disability and homelessness. Journal of Intellectual Disability Research. 55, 4, 441-449

Mir, B. and Oakie, E. (2007) 'A Study of the experience of Black and Asian young people whose behaviour is sexually harmful. in MM.C. Calder, (ed.) Working with Children and Young People who Sexually Abuse: Taking the field forward. Lyme Regis: Russell House Publishing Ltd

Morgan, W. (1996) London Offender Study: Creating Criminals: Why are so many criminals dyslexic? PhD dissertation. London: University of London

Nalavany, B.A., Carawan, L.W. and Sauber, S. (2013) Adults with dyslexia, an invisible disability: The mediational role of concealment on perceived family support and selfesteem. British Journal of Social Work, 18, 1, 58-749

National Audit Office (2014) Adult Social Care in England: Overview. London: Department of Health, Department for Communities and Local Government

Olisa, J., Patterson, J., and Wright, F. (2010) Homeless Literacy Report, London: A Thames Reach Action Research Report

Parsell, C and Marston, G. (2012) Beyond the 'at risk' individual:Housing and the eradication 
of poverty to prevent homelessness. Australian Journal of Public Administration. 71, 1, 33-44 Patterson, M. L., Moniruzzaman, A. Frankish, C. J. Somers, J. M. (2012) Missed opportunities: childhood learning disabilities as early indicators of risk among homeless adults with mental illness in Vancouver, British Columbia. BMJ Open: e001586 doi:10.1136/ bmjopen-2012-001586

Pluck, G. Lee, K., David, R., Macleod, D. C., Spence, S. A., and Parks, R. W. (2011) Neurobehavioural and cognitive function is linked to childhood trauma in homeless adults. British Journal of Clinical Psychology, 50, 33-45

Reindal, S. M. (2008). A Social relational model of disability: A theoretical framework for special needs education? European Journal of Special Needs Education. 23, 2, 135-146

Reeve. K and Batty, E. (2011) The Hidden Truth About Homelessness. Experiences of single homelessness in England. London: The Centre for Regional Economic and Social Research and Crisis

Rice, M. (1998) Dyslexia and Crime: Some notes on the dispel claim. Unpublished article, Institute of Criminology, UK. Cambridge: University of Cambridge

Samuelsson, S., Herkner, B. and I. Lundberg. (2003) Reading and writing difficulties among prison inmates: A matter of experiential factors rather than dyslexic problems. Scientific Studies of Reading, 7, 1, 53-73

Selenius, H., A.M. Daderman, A.W. Meurling, and S. Levander. (2006) Assessment of dyslexia in a group of male offenders with immigrant backgrounds undergoing a forensic psychiatric investigation. Journal of Forensic Psychiatry \& Psychology 17, 1, 1-22

Shakespeare, T. (2006; 2013). Disability Rights and Wrongs. London: Routledge

Taylor, H., Stuttaford, M., Broad, B \& P., Vostanis, (2006) Why a 'roof' is not enough: The characteristics of young homeless people referred to a designated mental health service. Journal of Mental Health, 15, 4, 491-501

Wilson, W. (2015) Homelessness in England. London: Social Policy Section House of Commons Wormer, R. V. (2004) Homelessness among older adults with severe mental illness: Abiologically based developmental perspective. Journal of Human Behavior in the Social Environment, 10 ,4, 39-49

Yates, P. R. (2013) Bad mouthing, bad habits and bad, bad boys: An exploration of the relationship between dyslexia and drug dependence. Mental Health and Substance Use: $6,3,184-202$ 